\title{
Endoscopic Ultrasonography-Guided Ethanol Ablation for Small Pancreatic Neuroendocrine Tumors: Results of a Pilot Study
}

\author{
Do Hyun Park', Jun-Ho Choi², Dongwook Oh¹, Sang Soo Lee', Dong-Wan Seo', Sung Koo Lee ${ }^{1}$ and \\ Myung-Hwan Kim ${ }^{1}$ \\ ${ }^{1}$ Division of Gastroenterology, Department of Internal Medicine, Asan Medical Center, University of Ulsan College of Medicine, Seoul, ${ }^{2}$ Department \\ of Internal Medicine, Dankook University College of Medicine, Cheonan, Korea
}

See commentary on page $94-95$

Background/Aims: Endoscopic ultrasonography (EUS)-guided ethanol ablation is gaining popularity for the treatment of focal pancreatic lesions. The aim of this study was to evaluate the safety, feasibility, and treatment response after EUS-guided ethanol injection for small pancreatic neuroendocrine tumors (p-NETs).

Methods: This was a retrospective analysis of a prospectively collected database including 11 consecutive patients with p-NETs who underwent EUS-guided ethanol injection.

Results: EUS-guided ethanol injection was successfully performed in 11 patients with 14 tumors. The final diagnosis was based on histology and clinical signs as follows: 10 non-functioning neuroendocrine tumors and four insulinomas. During follow-up (median, 370 days; range, 152 to 730 days), 10 patients underwent clinical follow-up after treatment, and one patient was excluded because of loss to follow-up. A single treatment session with an injection of 0.5 to $3.8 \mathrm{~mL}$ of ethanol resulted in complete responses (CRs) at the 3-month radiologic imaging for seven of 13 tumors (response rate, 53.8\%). Multiple treatment sessions performed in three tumors with residual viable enhancing tissue increased the number of tumors with CRs to eight of 13 (response rate, 61.5\%). Mild pancreatitis occurred in three of 11 patients.

Conclusions: EUS-guided ethanol injection appears to be a safe, feasible, and potentially effective method for treating small p-NETs in patients who are poor surgical candidates.

Key Words: Endosonography; Ethanol; Ablation; Neuroendocrine tumors

\section{INTRODUCTION}

Pancreatic neuroendocrine tumors (p-NETs) are fairly rare, accounting for $1 \%$ to $2 \%$ of primary pancreatic malignancies. ${ }^{1}$ The incidence and prevalence of $\mathrm{p}$-NETs have increased sub-

Received: April 7, 2014 Revised: July 9, 2014

Accepted: July 22, 2014

Correspondence: Do Hyun Park

Division of Gastroenterology, Department of Internal Medicine, Asan Medical Center, University of Ulsan College of Medicine, 88 Olympic-ro, Songpagu, Seoul 138-736, Korea

Tel: +82-2-3010-3194, Fax: +82-2-485-5782, E-mail: dhpark@amc.seoul.kr Do Hyun Park and Jun-Ho Choi contributed equally to this work as first authors.

( This is an Open Access article distributed under the terms of the Creative Commons Attribution Non-Commercial License (http://creativecommons.org/ licenses/by-nc/3.0) which permits unrestricted non-commercial use, distribution, and reproduction in any medium, provided the original work is properly cited. stantially recently, possibly because of the widespread use of advanced endoscopic and radiological imaging. ${ }^{2}$ The clinical presentation of $\mathrm{p}$-NETs varies strikingly in terms of symptoms and outcomes. ${ }^{3}$ The overall 5-year survival rate ranges from $30 \%$ for nonfunctioning neuroendocrine tumors to $97 \%$ for benign insulinomas. ${ }^{4}$ Treatment for $\mathrm{p}$-NETs should be highly tailored on the basis of the extent of disease, associated symptoms, presence of extrahepatic metastasis, and patient performance status. For patients with resectable tumors $>2 \mathrm{~cm}$, surgical resection is the standard of care. ${ }^{5}$ On the contrary, for those with nonfunctioning small $(<2 \mathrm{~cm})$ p-NETs, for which no study has revealed a survival benefit of surgery, ${ }^{5,6}$ the benefit of surgery must be balanced against operative morbidity and mortality.

Endoscopic ultrasonography-guided fine-needle aspiration 
(EUS-FNA) for pancreatic lesions is considered a minimally invasive diagnostic tool, and EUS-guided pancreatic injection of ethanol or other chemotherapeutic agents has been reported with few procedural complications. ${ }^{7}$ Ethanol is the most commonly used ablative agent for focal pancreatic and hepatic lesions. ${ }^{7-9}$ EUS-guided ethanol ablation has been recently proposed for the treatment of p-NETs. ${ }^{10-13}$ Levy et al. ${ }^{12}$ reported that ultrasonography-guided ethanol ablation for insulinoma is technically feasible and safe, and symptomatic improvement was achieved in all eight patients (100\%). However, these studies only included a small number of patients with functioning insulinomas. The aim of this pilot study was to investigate the safety, feasibility, and treatment response after EUS-guided ethanol injection for small p-NETs including nonfunctioning endocrine tumors.

\section{MATERIALS AND METHODS}

\section{Data source and study population}

Between February 2012 and February 2013, patients with suspicious $\mathrm{p}$-NETs on imaging results and/or clinical features who were referred for differential diagnosis and management were enrolled in this study using specific inclusion and exclusion criteria. The diagnosis of p-NET was based on clinical and characteristic imaging findings, such as well-demarcated and hypervascular mass lesions in the pancreas (Fig. 1A). The presence of a p-NET was further confirmed by p-NET cytology or histopathology from a core biopsy specimen. A diagnosis of insulinoma was suspected in patients with symptomatic fasting hypoglycemia, which includes: (1) symptoms and signs of hypoglycemia, (2) concomitant plasma glucose level of $\leq 45 \mathrm{mg} / \mathrm{dL}$, and (3) reversibility of symptoms with glucose administration. A total of 11 patients were enrolled in the study, and they subsequently underwent EUS-guided fine-needle injection of 99\% pure ethanol. The study was approved by the Institutional Review Board of the Asan Medical Center (Seoul, Korea), and written informed consent was obtained from all patients.

The inclusion criteria were as follows: (1) a p-NET $<2 \mathrm{~cm}$ in diameter, (2) low suitability for surgery (multifocal location, American Society of Anesthesiologist physical status classification grade III or IV), (3) refusal of surgery, and (4) follow-up for $>3$ months after EUS-guided ethanol injection. The exclusion criteria were as follows: (1) refusal to participate in the study, (2) overt carcinomas, (3) bleeding tendency (prothrombin time $>1.5$ international normalized ratio or a platelet count $<50,000 / \mu \mathrm{L}$ ), (4) age $<18$ years, (5) pregnancy, and (6) active acute pancreatitis.

\section{Procedures}

\section{EUS-guided intervention}

All EUS procedures were performed after the patient was consciously sedated using midazolam and meperidine. To prevent acute pancreatitis and infection, a prophylactic antibiotic (ceftizoxime or ceftriaxone) and antiprotease prophylaxis (gabexate mesylate $300 \mathrm{mg}$ in saline solution $500 \mathrm{~mL}$, starting before the procedure and continuing for 24 hours) were intravenously administered.

The procedures were performed according to the following scheme:

(1) Step 1: diagnostic contrast-enhanced harmonic EUS (CEH-EUS) with FNA was performed to confirm the neuroendocrine nature of the tumor. A curvilinear array echoendoscope (GF-UCT 240-AL 10; Olympus Medical System, Tokyo, Japan) was used to perform both CEH-EUS and FNA. The ultrasound processor was the Aloka Prosound Alpha 10 (Aloka Co., Ltd., Tokyo, Japan), which incorporates dedicated software for CEH-EUS. After a complete EUS examination of the pancreas in B-mode, the echoendoscope was switched to the CEH-EUS mode. SonoVue (Bracco, Milan, Italy) was used as a contrast agent. A bolus infusion of $2.5 \mathrm{~mL}$ of SonoVue into an antecubital vein was followed by injection of $10 \mathrm{~mL}$ of saline solution. EUS-FNA was performed using a 22-gauge needle (EchoTip Ultra or ProCore; Cook Endoscopy, Winston Salem, NC, USA).

(2) Step 2: EUS-guided ethanol injection: the FNA needle was introduced into the tumor under real-time EUS. The optimal volume of ethanol (99\%) injected into the tumor was determined according to the size of the tumor and calculated by computer estimation of areas on each axial image using EUS software permitting volume calculation (Fig. 1B). Then, the needle was advanced into the tumor (Fig. 1C), and the injections were repeated until the hyperechoic blush extended to the margin of the tumor (Fig. 1D). At the end of ablation, EUS revealed an echogenic cloud in the mass. All patients were closely monitored for possible adverse events, including abdominal pain, bleeding, and infection, while maintaining a 24hour restriction on food. Patients were discharged 2 days after the procedure if no adverse events developed.

\section{Follow-up protocol}

The study profile is outlined in Fig. 2. After discharge, patients were followed up every 3 months on an outpatient basis for the first 2 years. The first follow-up contrast-enhanced computed tomography (CECT) was performed at 3 months after the procedure. At 3 months after the first CECT, residual viable tumor was considered present if enhanced areas were noted within the tumors on either the arterial phase or portal 
venous phase images. CEH-EUS was performed if there was uncertainty concerning the CECT findings regarding whether residual viable tumor was present. Further follow-up CECT was performed at 3-month intervals if an incomplete response was observed on the first follow-up CECT and at 6-month intervals if a complete response was observed on the first followup CECT. If a complete response was documented on two consecutive follow-up images, then a yearly follow-up was planned.

\section{Main outcome measurements and definitions of clinical outcomes}

The primary purpose of this study was to evaluate the technical feasibility and safety of EUS-guided ethanol injection in patients with $\mathrm{p}$-NETs. The procedure was defined as feasible if the fine needle injection of ethanol inside the tumor was suc-
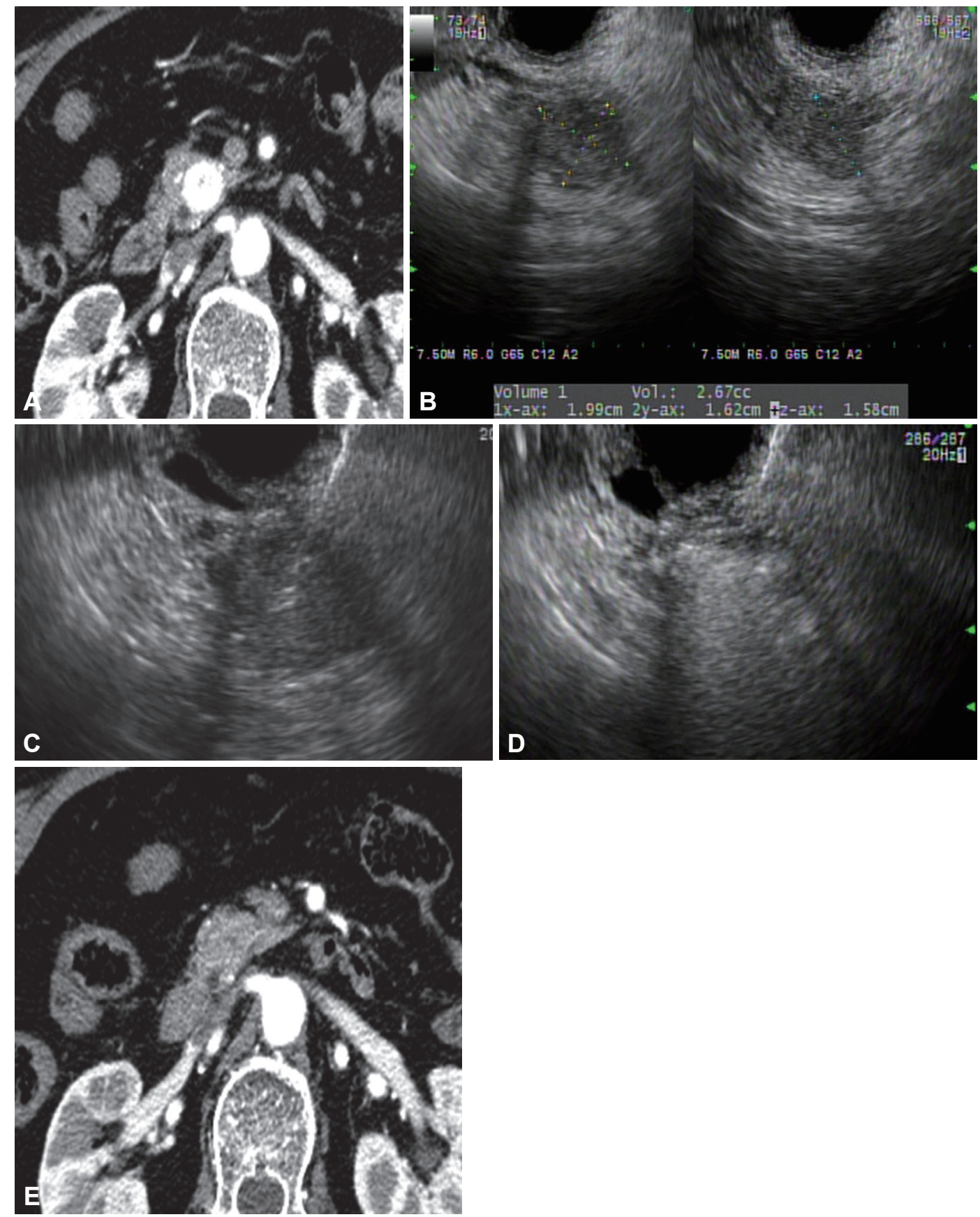

Fig. 1. (A) Contrast-enhanced computed tomography (CT) scan showing a hypervascular mass in the pancreatic head. (B) Sonographic volumetric analysis of the tumor using 3-dimensional software. (C) Endoscopic ultrasonography-guided puncture of a neuroendocrine tumor. (D) Use of a 22-gauge needle for multiple injections of $99 \%$ ethanol until the hyperechoic blush extended to the margin of the tumor. (E) Eight-month follow-up CT scan showing successful ethanol ablation of a tumor. 
cessful. An early adverse event was defined as any procedurerelated complication occurring within the first week. A late adverse event was defined as any complications arising at the site of the tumor within 3 months of the procedure. The secondary endpoint was the treatment response rate.

Tumor viability was assessed using CECT and/or CEH-EUS after ablation. CECT/CEH-EUS disclosed a devascularized, hypodense area at the site of ablation (Fig. 1E). CECT was reviewed by an expert radiologist, and an independent observer evaluated the microvasculature and parenchymal perfusion on CEH-EUS. Treatment responses were assessed according to enhanced residual tumor areas on CECT and/or CEH-EUS. Treatment responses were categorized as complete (the disappearance of any enhanced area within the tumors) or incomplete responses (persistence of enhanced tumor). Recurrence was defined as the development of enhancing tumor within the ablation zone and/or the appearance of a new lesion on followup CECT and/or CEH-EUS.

\section{RESULTS}

\section{Patient characteristics}

Eleven patients were enrolled during the study period. The patients and tumor characteristics are described in Table 1. Six patients were women (55\%), and the mean age of the patients was 52.5 years (range, 27 to 76 ). The mean size of the lesion was $12.2 \mathrm{~mm}$ (range, 8 to 19), and the most common location was within the head of the pancreas $(n=6,42.9 \%)$. The final diagnosis was based on histology and clinical signs as follows: 10 non-functioning neuroendocrine tumors and four insulinomas. Two patients had symptomatic hypoglycemia, and insulinoma was confirmed by biochemical analysis. Multiple tumors were identified in two patients with multiple endocrine neoplasia type 1 syndrome.

The operation could not be performed because of the location of the tumor requiring pancreaticoduodenectomy $(n=3)$, patient refusal $(n=4)$, and underlying comorbidities $(n=4)$.

\section{Feasibility and safety}

All patients tolerated the EUS procedure. EUS-guided fine needle injection of ethanol was successfully performed in all 11 patients, who had 14 tumors in total, and a total of 18 treatment sessions were performed (Table 2). For six patients, a single treatment session was performed. Five patients underwent two $(n=3)$ or three $(n=2)$ treatment sessions. Nine patients had solitary pancreatic lesions, and two patients had

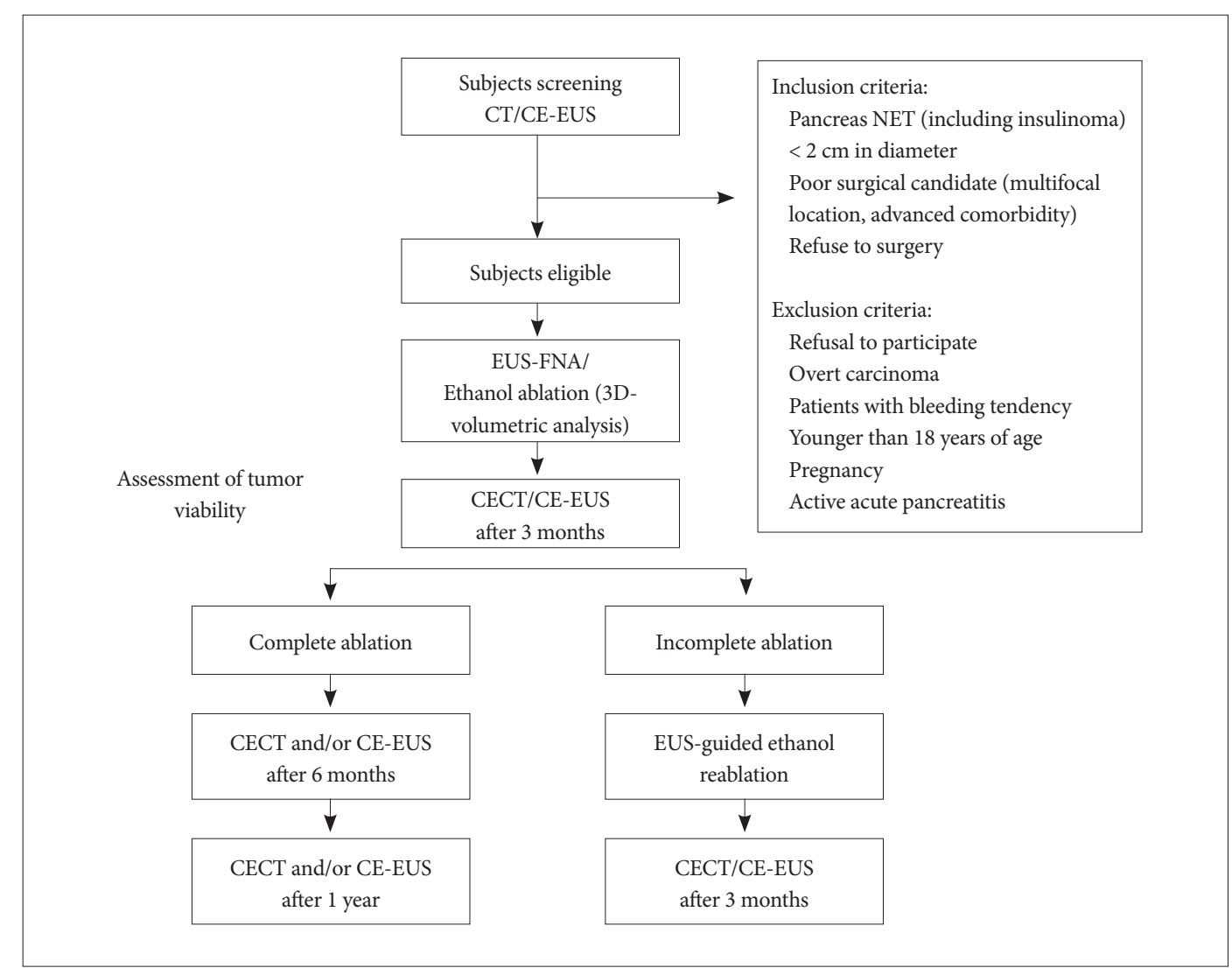

Fig. 2. Study flowchart. CT, computed tomography; CE-EUS, contrast-enhanced endoscopic ultrasonography; NET, neuroendocrine tumor; EUS-FNA, endoscopic ultrasonography-guided fine-needle aspiration; 3D, 3-dimensional; CECT, contrast-enhanced computed tomography. 
multiple lesions. Of the latter two patients, one patient had three tumors in the pancreas, and the other had two tumors. The median volume of ethanol injected per treatment session was $1.6 \mathrm{~mL}$ (range, 0.5 to 3.8). Multiple injections were performed until ethanol appeared to have been injected throughout the tumor.

The following complications occurred soon after the proce-

Table 1. Baseline Characteristics of the Patients and Tumors

\begin{tabular}{lc}
\multicolumn{1}{c}{ Characteristic } & Value \\
\hline No. of patients who underwent EUS-FNI & 11 \\
No. of tumors & 14 \\
Age, yr & $52.5 \pm 20.5$ \\
Sex, male/female & $5 / 6$ \\
Tumor size, mm & $12.3 \pm 3.2(8-19)$ \\
Location of the tumors & \\
Uncinate & $1(7.1)$ \\
$\quad$ Head & $6(42.9)$ \\
Body/tail & $7(50.0)$ \\
Incidental discovery & $9(81.8)$ \\
Hypoglycemia-related symptoms & $2(18.2)$ \\
\hline
\end{tabular}

Values are presented as mean \pm SD, mean \pm SD (range), or number (\%). EUS-FNI, endoscopic ultrasonography-guided fine needle injection. dure: mild pancreatitis $(n=3)$ and vague abdominal pain lasting for 1 day $(n=1)$. One patient, who had been previously treated for mild pancreatitis, developed abdominal pain 1 month after the ablation. The patient underwent endoscopic retrograde cholangiopancreatography, which confirmed pancreatic duct stricture requiring stent placement.

\section{Treatment response}

Ten patients with 13 tumors were followed up for a median of 370 days (range, 182 to 730 ) after EUS-guided ethanol fine needle injection, and one patient was lost to follow-up and excluded from the treatment analysis. Treatment responses are summarized in Table 3. A single treatment session resulted in complete tumor ablation at the 3-month radiologic imaging of seven of 13 tumors (response rate, 53.8\%). Multiple treatment sessions were performed for three tumors with enhanced residual viable tissue, which increased the number of tumors with a complete response to eight of 13 (response rate, 61.5\%). None of these patients developed progressive disease during follow-up. The rate of local complete response was $61.5 \%$. Patients who exhibited incomplete responses after multiple sessions of ethanol ablation received clinical follow-up. Two patients with insulinoma demonstrated the complete absence of hypoglycemic symptoms after treatment.

Table 2. Procedural Outcomes of Endoscopic Ultrasonography-Guided Ethanol Ablation (Data for the 14 Tumors in the 11 Patients)

\begin{tabular}{|c|c|c|c|c|c|c|c|c|c|}
\hline $\mathrm{Pt}$ & $\begin{array}{l}\text { Age, } \\
\text { yr }\end{array}$ & Sex & $\begin{array}{c}\text { Hypoglycemia-related } \\
\text { symptoms }\end{array}$ & Site & $\begin{array}{l}\text { Size, } \\
\mathrm{mm}\end{array}$ & $\begin{array}{l}\text { Treatment session } \\
\qquad(n=18)\end{array}$ & $\begin{array}{c}\text { Ethanol volume, } \\
\mathrm{mL}\end{array}$ & $\begin{array}{c}\text { Early adverse } \\
\text { events }\end{array}$ & $\begin{array}{c}\text { Late adverse } \\
\text { events }\end{array}$ \\
\hline \multirow[t]{2}{*}{1} & 66 & $\mathrm{~F}$ & Present & Head & $13 \times 10$ & 1 of 2 & 2.6 & & \\
\hline & & & & & & 2 of 2 & 3.8 & & \\
\hline \multirow[t]{3}{*}{2} & 27 & $\mathrm{~F}$ & Present & Head & $17 \times 9$ & 1 of 1 & 1.0 & & \\
\hline & & & & Body & $10 \times 8$ & 1 of 1 & 1.0 & & \\
\hline & & & & Tail & $10 \times 9$ & 1 of 1 & 1.2 & & \\
\hline \multirow[t]{2}{*}{3} & 30 & M & Absent & Head & $12 \times 9$ & 1 of 1 & 7.0 & Pancreatitis & $\begin{array}{l}\text { Pancreatic } \\
\text { duct stricture }\end{array}$ \\
\hline & & & & Head & $6 \times 4$ & 1 of 1 & 4.0 & & \\
\hline \multirow[t]{2}{*}{4} & 27 & M & Absent & Head & $8 \times 8$ & 1 of 2 & 0.8 & & \\
\hline & & & & & & 2 of 2 & 1.5 & & \\
\hline \multirow[t]{3}{*}{5} & 31 & M & Absent & Body & $12 \times 8$ & 1 of 3 & 2.3 & & \\
\hline & & & & & & 2 of 3 & 1.7 & & \\
\hline & & & & & & 3 of 3 & 0.5 & Pancreatitis & \\
\hline 6 & 74 & $\mathrm{~F}$ & Absent & $\begin{array}{l}\text { Uncinate } \\
\text { process }\end{array}$ & $19 \times 14$ & 1 of 1 & 2.4 & Pancreatitis & \\
\hline 7 & 71 & $\mathrm{~F}$ & Absent & Tail & $12 \times 9$ & 1 of 1 & 1.0 & Abdominal pain & \\
\hline 8 & 45 & $\mathrm{~F}$ & Absent & Head & $10 \times 9$ & 1 of 1 & 2.5 & & \\
\hline 9 & 67 & $\mathrm{M}$ & Absent & Body & $11 \times 11$ & 1 of 1 & 0.5 & & \\
\hline 10 & 64 & $\mathrm{~F}$ & Absent & Body & $12 \times 9$ & 1 of 1 & 1.6 & & \\
\hline 11 & 76 & $\mathrm{M}$ & Absent & Tail & $9 \times 9$ & 1 of 1 & 1.0 & & \\
\hline
\end{tabular}

Pt, patient; M, male; F, female. 
Table 3. Treatment Response after Endoscopic Ultrasonography-Guided Ethanol Ablation (Data for the 14 Tumors in the 11 Patients)

\begin{tabular}{clclc}
\hline Patient & \multicolumn{1}{c}{ Indication } & Associated symptoms & Treatment response & Follow-up period, day \\
\hline 1 & Insulinoma & Disappeared & Incomplete response & 365 \\
2 & Insulinoma & Disappeared & Complete response & 730 \\
& Insulinoma & & Complete response & 730 \\
& Insulinoma & & Complete response & 730 \\
3 & Nonfunctioning neuroendocrine tumor & Absent & Incomplete response & 710 \\
& Nonfunctioning neuroendocrine tumor & & Complete response & 710 \\
4 & Nonfunctioning neuroendocrine tumor & Absent & Incomplete response & 100 \\
5 & Nonfunctioning neuroendocrine tumor & Absent & Complete response & 396 \\
6 & Nonfunctioning neuroendocrine tumor & Absent & Complete response & 425 \\
7 & Nonfunctioning neuroendocrine tumor & Absent & & Loss to follow-up \\
8 & Nonfunctioning neuroendocrine tumor & Absent & Complete response & 365 \\
9 & Nonfunctioning neuroendocrine tumor & Absent & Complete response & 271 \\
10 & Nonfunctioning neuroendocrine tumor & Absent & Complete response & 110 \\
11 & Nonfunctioning neuroendocrine tumor & Absent & Incomplete response & 120 \\
\hline
\end{tabular}

\section{DISCUSSION}

There is growing interest and a need to use ethanol ablation to treat pancreatic lesions. This pilot study demonstrated that EUS-guided ethanol injection for $\mathrm{p}$-NETs appears feasible as a potentially effective treatment with acceptable complication rates.

Ethanol has gained popularity as an ablative agent because it is inexpensive, is readily available, and has the potential to ablate tissue. The mechanism of ethanol ablation involves coagulation necrosis of the tumor as a result of cellular dehydration, protein denaturation, and vascular occlusion. ${ }^{14,15}$ Matthes et al. ${ }^{16}$ reported a pilot study of EUS-guided fine needle injection of ethanol into the porcine pancreas, which resulted in localized tissue necrosis without complications. The major limitations of ethanol ablation are the possibility of late recurrence that would require retreatment, incomplete ablation, and the risk of progression during follow-up. It is important to note that complete treatment response in this study was assessed using follow-up enhanced imaging modality rather than histopathologic correlation. Injected ethanol may not always induce complete tumor ablation because of its inhomogeneous distribution within the tumor and its limited effects on extracapsular cancerous spread. ${ }^{17}$ Physicians should consider the existing potential for residual tumor and progression. EUS-guided ethanol ablation should therefore be reserved for patients who refuse surgery or who are poor surgical candidates. Long-term follow-up study after ablation is needed before patients are considered cured of the disease.

Safety is an important issue in the potential clinical application of EUS-guided ethanol ablation. As with any ablative procedure, the main concern will be the risk of acute pancreatitis, which can result from the dispersion of ethanol outside the lesion and into the surrounding pancreatic parenchyma and/or the main pancreatic duct. A previous animal study that examined ablation of the porcine pancreas using ethanol injections reported that the area of inflammatory change associated with the injected ethanol is concentration-dependent, and local pancreatitis can occur. ${ }^{9}$ In our study, three cases of mild pancreatitis occurred (27.2\%). One patient developed pancreatic duct stricture as a late adverse event. The risk of developing pancreatitis appears to be associated with the total amount of ethanol injected into the tumor during the treatment session; specifically, all procedure-associated cases of pancreatitis occurred when $>2 \mathrm{~mL}$ of ethanol were administered in a session. Different methods of increasing therapeutic efficacy, as well as avoiding the problems of pancreatitis, should be further explored.

It is difficult to satisfactorily measure the extent of ablation using CECT alone. CEH-EUS is increasingly used for the characterization of solid pancreatic masses. ${ }^{18}$ Previous research demonstrated that CEH-EUS can be used both to detect pNET and monitor necrotic areas caused by ethanol ablation. ${ }^{19}$ In this study, we used CEH-EUS to facilitate the detection of p-NETs and postablation follow-up, and small hypovascular necrotic lesions were clearly observed because of substantial differences (e.g., the absence of contrast flow inside successful ablation sites and the surrounding enhanced normal pancreatic tissues).

Our study has several limitations. The number of patients was small, and the follow-up period may not have been sufficient to identify late tumor recurrence. Another weakness is the uncontrolled, retrospective study design. Nonetheless, our current pilot study is a useful forerunner of a large trial with a 
long-term follow-up period to fully elucidate the clinical benefits of EUS-guided ethanol ablation for p-NETs.

In conclusion, EUS-guided ethanol ablation is technically feasible and relatively safe, with a $61 \%$ treatment response rate in patients with p-NETs. Some improvements in the ablative agent and methodology are needed; however, this minimally invasive procedure could potentially be used to limit local tumor growth in patients who are unsuitable for surgery.

\section{Conflicts of Interest}

The authors have no financial conflicts of interest.

\section{Acknowledgments}

This study was supported by a 2013 Weolbong grant from the Korean Gastrointestinal Endoscopy Foundation (2013 Investigation Grant).

\section{REFERENCES}

1. O'Grady HL, Conlon KC. Pancreatic neuroendocrine tumours. Eur J Surg Oncol 2008;34:324-332.

2. Modlin IM, Oberg K, Chung DC, et al. Gastroenteropancreatic neuroendocrine tumours. Lancet Oncol 2008;9:61-72.

3. Cherenfant J, Stocker SJ, Gage MK, et al. Predicting aggressive behavior in nonfunctioning pancreatic neuroendocrine tumors. Surgery 2013; 154:785-791.

4. Oberg K, Eriksson B. Endocrine tumours of the pancreas. Best Pract Res Clin Gastroenterol 2005;19:753-781.

5. Falconi M, Plockinger U, Kwekkeboom DJ, et al. Well-differentiated pancreatic nonfunctioning tumors/carcinoma. Neuroendocrinology 2006;84:196-211.

6. Bettini R, Partelli S, Boninsegna L, et al. Tumor size correlates with malignancy in nonfunctioning pancreatic endocrine tumor. Surgery 2011; 150:75-82.

7. Oh HC, Seo DW, Song TJ, et al. Endoscopic ultrasonography-guided ethanol lavage with paclitaxel injection treats patients with pancreatic cysts. Gastroenterology 2011;140:172-179.

8. Larssen TB, Rosendahl K, Horn A, Jensen DK, Rørvik J. Single-session alcohol sclerotherapy in symptomatic benign hepatic cysts performed with a time of exposure to alcohol of $10 \mathrm{~min}$ : initial results. Eur Radiol 2003;13:2627-2632.

9. Aslanian H, Salem RR, Marginean C, Robert M, Lee JH, Topazian M. EUS-guided ethanol injection of normal porcine pancreas: a pilot study. Gastrointest Endosc 2005;62:723-727.

10. Deprez PH, Claessens A, Borbath I, Gigot JF, Maiter D. Successful endoscopic ultrasound-guided ethanol ablation of a sporadic insulinoma. Acta Gastroenterol Belg 2008;71:333-337.

11. Jürgensen C, Schuppan D, Neser F, Ernstberger J, Junghans U, Stölzel U. EUS-guided alcohol ablation of an insulinoma. Gastrointest Endosc 2006;63:1059-1062.

12. Levy MJ, Thompson GB, Topazian MD, Callstrom MR, Grant CS, Vella A. US-guided ethanol ablation of insulinomas: a new treatment option. Gastrointest Endosc 2012;75:200-206.

13. Vleggaar FP, Bij de Vaate EA, Valk GD, Leguit RJ, Siersema PD. Endoscopic ultrasound-guided ethanol ablation of a symptomatic sporadic insulinoma. Endoscopy 2011;43(Suppl 2 UCTN):E328-329.

14. Zhang WY, Li ZS, Jin ZD. Endoscopic ultrasound-guided ethanol ablation therapy for tumors. World J Gastroenterol 2013;19:3397-3403.

15. Gelczer RK, Charboneau JW, Hussain S, Brown DL. Complications of percutaneous ethanol ablation. J Ultrasound Med 1998;17:531-533.

16. Matthes K, Mino-Kenudson M, Sahani DV, Holalkere N, Brugge WR. Concentration-dependent ablation of pancreatic tissue by EUS-guided ethanol injection. Gastrointest Endosc 2007;65:272-277.

17. Lencioni R, Crocetti L, Cioni D, et al. Single-session percutaneous ethanol ablation of early-stage hepatocellular carcinoma with a multipronged injection needle: results of a pilot clinical study. J Vasc Interv Radiol 2010;21:1533-1538.

18. Kitano M, Sakamoto H, Kudo M. Endoscopic ultrasound: contrast enhancement. Gastrointest Endosc Clin N Am 2012;22:349-358.

19. Giday SA, Magno P, Gabrielson KL, et al. The utility of contrast-enhanced endoscopic ultrasound in monitoring ethanol-induced pancreatic tissue ablation: a pilot study in a porcine model. Endoscopy 2007; 39:525-529. 